\title{
REVIEW
}

\section{Clinical review: Intra-abdominal hypertension: does it influence the physiology of prone ventilation?}

\author{
Andrew W Kirkpatrick, ${ }^{1,23 *}$, Paolo Pelosi ${ }^{4}$, Jan J De Waele ${ }^{5}$, Manu LNG Malbrain ${ }^{6}$, Chad G Ball, ${ }^{1,2}$, Maureen O Meade ${ }^{7,8}$,
} Henry T Stelfox ${ }^{3}$ and Kevin B Laupland ${ }^{3}$

\begin{abstract}
Prone ventilation (PV) is a ventilatory strategy that frequently improves oxygenation and lung mechanics in critical illness, yet does not consistently improve survival. While the exact physiologic mechanisms related to these benefits remain unproven, one major theoretical mechanism relates to reducing the abdominal encroachment upon the lungs. Concurrent to this experience is increasing recognition of the ubiquitous role of intra-abdominal hypertension (IAH) in critical illness, of the relationship between IAH and intra-abdominal volume or thus the compliance of the abdominal wall, and of the potential difference in the abdominal influences between the extrapulmonary and pulmonary forms of acute respiratory distress syndrome. The present paper reviews reported data concerning intra-abdominal pressure (IAP) in association with the use of PV to explore the potential influence of IAH. While early authors stressed the importance of gravitationally unloading the abdominal cavity to unencumber the lung bases, this admonition has not been consistently acknowledged when PV has been utilized. Basic data required to understand the role of IAP/IAH in the physiology of PV have generally not been collected and/or reported. No randomized controlled trials or meta-analyses considered IAH in design or outcome. While the act of proning itself has a variable reported effect on IAP, abundant clinical and laboratory data confirm that the thoracoabdominal cavities are intimately linked and that IAH is consistently transmitted across the diaphragm - although the transmission ratio is variable and is possibly related to the compliance of the abdominal wall. Any proning-related intervention that secondarily influences IAP/IAH is likely to greatly influence respiratory mechanics and outcomes. Further study of the role of IAP/IAH in the physiology and outcomes of $\mathrm{PV}$ in hypoxemic respiratory failure is thus required. Theories relating inter-relations between prone positioning and the abdominal condition are presented to aid in designing these studies.
\end{abstract}

\section{Introduction}

Patients with acute respiratory failure frequently require mechanical ventilation (MV). Unfortunately MV can further damage the lungs and worsen respiratory failure through a variety of mechanisms $[1,2]$. Prone ventilation (PV) by means of prone positioning (PP) has been proposed as a strategy that may rescue the sickest patient from refractory hypoxemia [1,3-6], although identifying a survival benefit has proven difficult [4,7-12]. PV may also ameliorate the underlying physical strain and generation of inflammatory mediators that compound ventilatorinduced lung injury [13-16]. Further, as a technologically

*Correspondence: andrew.kirkpatrick@albertahealthservices.ca 'Regional Trauma Services, Foothills Medical Centre, 140329 Street NW, Calgary, Alberta, Canada T2N 2T9

Full list of author information is available at the end of the article simple intervention, PV could conceivably benefit patients in countries where more expensive respiratory technologies are unavailable. There is therefore reason to further explore specific mechanisms and patient groups who might benefit [5,7,17-19].

One of the most frequent causes of acute respiratory failure requiring MV is acute respiratory distress syndrome (ARDS), reflecting the more severe spectrum of acute lung injury (ALI) [20,21]. The initial consensus definitions recognized two inciting pathways for ALI/ ARDS: pulmonary and extrapulmonary - reflecting either direct lung injury or indirect injuries to the pulmonary endothelium as mediated by the systemic inflammatory response [20,21]. In particular, the influence of the abdomen appears to differ between pulmonary and extrapulmonary causes, differently affecting chest wall mechanics [21-28] - with higher intra-abdominal pressure (IAP) in extrapulmonary ALI/ARDS often related to greater and more recruitable lung collapse $[24,26]$. 
The World Society of the Abdominal Compartment Syndrome defines intra-abdominal hypertension (IAH) as sustained IAP $\geq 12 \mathrm{mmHg}$, and defines the abdominal compartment syndrome (ACS) as IAP $>20 \mathrm{mmHg}$ with new organ failure [29]. IAH is a condition that can complicate virtually any critical condition, greatly influences the respiratory system and associates with adverse clinical outcomes [30]. Obesity and high body mass index (BMI) are inter-related characteristics associated with IAH that also impair respiratory mechanics [30,31]. Although the study of PV was initiated in 1974 after Bryan suggested the technique as a means of alleviating intrusion of the abdominal contents upon the thoracic volume [32], the role of the abdomen in general, and of IAH in particular, has been largely ignored in subsequent studies. Many pioneers of PV considered it critical to unload or suspend the abdominal cavity while proning. In 1977 Douglas and colleagues predicted that protuberant abdomens which were not suspended adequately would 'have little or no improvement or may even have a deterioration in $\mathrm{PaO}_{2}$ when turned prone' [33]. We therefore reviewed both the reported experiences and possible influence of the abdominal status in PV research.

\section{Materials and methods}

The MEDLINE, EMBASE, BioMed Central, CINAHL, and Cochrane databases were searched for original research concerning PV, IAP, IAH, and ACS. Bibliographies of all retrieved articles were reviewed to identify additional literature. One reviewer abstracted data from each study related to study type (animal versus clinical), study design (randomized trial, other controlled clinical, or physiologic study), population (setting, numbers), whether body weight was specifically positioned over the chest and pelvic bones (thoracopelvic support) and/or whether the abdomen was freely suspended to permit free abdominal movements independent of the bed (suspension), as well as baseline physiologic characteristics.

\section{Results \\ Data relating prone ventilation and intra-abdominal pressure \\ Animal studies}

Only two porcine studies measured IAP during PV; one with normal lungs [34], the other with an oleic-acid lunginjury model [35] (Table 1). Mure and colleagues used an inflatable balloon to distend the abdomen with normal lungs in either supine positioning or PP. They observed greater improvement in gas exchange after PP in the presence of abdominal distension than without [34]. Conversely, Colmenero-Ruiz and colleagues reported no differential effect on the oxygenation with proning when the abdomen was freely suspended in their normal lung model without IAH [35]. There are no reported animal data concerning injured lungs in the setting of abdominal distension or IAH.

\section{Human studies}

Effect of proning on intra-abdominal pressure in humans

Eight studies measured IAP during PV in critically ill patients, and another study concerned obese patients during elective surgery (Table 2). Two studies unloaded the abdomen [36,37] while five did not [38-42], and one study did not report on abdominal unloading [43]. Finally, one study randomized abdominal suspension [44].

Several authors reported that the PP raises IAP in certain situations [38-40]. Michelet and colleagues found that while gas exchange increased with either method, IAP significantly increased on the conventional mattresses from normal to grade II IAH [40]. Although not presented numerically, graphical analysis suggests that IAP increased from approximately 7 to $15 \mathrm{mmHg}$ on a conventional mattress and from 8 to $12 \mathrm{mmHg}$ on an aircushioned mattress during PP [40]. None of these patients had IAH prior to proning and all had pulmonary ALI/ARDS. Hering and colleagues reported two studies in which mixed pulmonary and extrapulmonary ALI patients who were proned on air-cushioned beds without suspension had mean IAP rises on average from 10 to $11 \mathrm{mmHg}$ up to 13 to $14 \mathrm{mmHg}[38,39]$. Kiefer and colleagues studied 25 patients (BMI and suspension not reported) requiring $\mathrm{MV}$, and found that the mean IAP was not significantly affected by proning [43]. Pelosi and colleagues measured IAP in 10 patients with ALI before and after PP with abdominal suspension, and noted that the mean IAP rose nonsignificantly from 11.4 to $14.8 \mathrm{mmHg}$ [36].

Chiumello and colleagues conducted the only randomized trial comparing abdominal suspension versus no suspension during PV. They studied 11 patients with mixed pulmonary and extrapulmonary ARDS [44]. They found an improvement in respiratory function with PV and an increase in IAP when turned to prone regardless of suspension or not [44]. Most recently, in 10 patients with pulmonary ARDS and initial IAP constituting grade II IAH (14.5 mmHg), Fletcher reported a small but statistically significant fall after proning [42].

\section{Reported consequences of prone positioning induced intra-} abdominal pressure changes in humans

Despite reports of statistically significant changes in IAP, consistent clinical effects have not been seen with these modest IAP changes [45]. Michelet and colleagues examined a number of parameters after proning [40]. They studied the disappearance rate of indocyanine green as a surrogate for splanchnic perfusion. While extravascular lung water and intrathoracic blood volume were unmodified, the disappearance rate of indocyanine green 
Table 1. Intra-abdominal pressure findings in prone ventilation studies involving animals

\begin{tabular}{|c|c|c|c|c|c|c|}
\hline Study & Animals & Intervention & $\begin{array}{l}\text { Abdomen } \\
\text { unloading? }\end{array}$ & $\begin{array}{c}\text { Mean supine } \\
\text { IAP } \\
(\mathrm{mmHg})\end{array}$ & $\begin{array}{c}\text { Mean prone } \\
\text { IAP } \\
(\mathrm{mmHg})\end{array}$ & Comments \\
\hline \multirow[t]{2}{*}{$\begin{array}{l}\text { Mure and } \\
\text { colleagues [34] }\end{array}$} & 8 pigs & Intra-abdominal & No & 7 (no distension) & 8 (no distension) & $\begin{array}{c}\text { Gas exchange most improved when } \\
\text { abdomen distended }\end{array}$ \\
\hline & & Balloon inflation & & 24 (distension) & 18 (distension) & \\
\hline \multirow[t]{2}{*}{$\begin{array}{l}\text { Colmenero-Ruiz and } \\
\text { colleagues [35] }\end{array}$} & 20 pigs & $\begin{array}{l}\text { Oleic acid } \\
\text { induced }\end{array}$ & Randomized & 3.7 (no suspension) & 6.5 (no suspension) & $\begin{array}{l}\text { No gas exchange benefits from } \\
\text { suspension }\end{array}$ \\
\hline & & Acute lung injury & & 3.4 (suspension) & 7.2 (suspension) & \\
\hline
\end{tabular}

IAP, intra-abdominal pressure.

Table 2. Prone ventilation in relation to intra-abdominal pressure and obesity

\begin{tabular}{|c|c|c|c|c|c|c|c|c|}
\hline \multirow[b]{2}{*}{ Study } & \multirow[b]{2}{*}{ Patients } & \multirow[b]{2}{*}{$\begin{array}{l}\text { Abdominal } \\
\text { unloading }\end{array}$} & \multirow[b]{2}{*}{$\begin{array}{c}\text { BMI } \\
\text { (mean) }\end{array}$} & \multicolumn{3}{|c|}{ Intra-abdominal pressure } & \multirow[b]{2}{*}{$\begin{array}{l}\text { ARDS } \\
\text { type }^{\text {b }}\end{array}$} & \multirow[b]{2}{*}{$\begin{array}{l}\text { Comments or } \\
\text { major conclusions }\end{array}$} \\
\hline & & & & $\begin{array}{l}\text { Zero, } \\
\text { prime }^{\mathrm{a}}\end{array}$ & $\begin{array}{c}\text { Mean } \\
\text { supine } \\
(\mathrm{mmHg})\end{array}$ & $\begin{array}{c}\text { Mean } \\
\text { prone } \\
(\mathrm{mmHg})\end{array}$ & & \\
\hline $\begin{array}{l}\text { Pelosi and } \\
\text { colleagues [37] }\end{array}$ & $10^{c}$ & Yes & 34.6 & NA & NR & NR & NA & $\begin{array}{l}\text { FRC increased } 1 \text { I, lung } \\
\text { compliance increased } 18 \mathrm{cmH}_{2} \mathrm{O}\end{array}$ \\
\hline $\begin{array}{l}\text { Pelosi and } \\
\text { colleagues [36] }\end{array}$ & $10^{d}$ & Yes & NR & $\begin{array}{l}\text { Symph., } \\
100 \mathrm{ml}\end{array}$ & 11.4 & $14.8(P=N S)$ & $12 \%$ EP & $\begin{array}{l}\text { Decreased chest wall } \\
\text { compliance. Oxygenation better }\end{array}$ \\
\hline $\begin{array}{l}\text { Hering and } \\
\text { colleagues [38] }\end{array}$ & 16 & No & NR & $\begin{array}{l}\text { Symph., } \\
250 \mathrm{ml}\end{array}$ & 12 & $15(P<0.05)$ & $21 \%$ EP & Renal function not impaired \\
\hline $\begin{array}{l}\text { Kiefer and } \\
\text { colleagues [43] }\end{array}$ & 25 & Not described & NR & $\begin{array}{l}\mathrm{NR}^{\mathrm{e}} \\
\mathrm{NA}\end{array}$ & 10 & $11(P=N S)$ & NR & $\begin{array}{l}\text { Gastric tonometry decrements } \\
\text { common }\end{array}$ \\
\hline $\begin{array}{l}\text { Hering and } \\
\text { colleagues [39] }\end{array}$ & 12 & No & 26 & $\begin{array}{l}\text { Symph., } \\
250 \mathrm{ml}\end{array}$ & 10 & $13(P<0.05)$ & $34 \%$ EP & Splanchnic perfusion OK \\
\hline $\begin{array}{l}\text { Matejovic and } \\
\text { colleagues [41] }\end{array}$ & 11 & No & NR & $\begin{array}{l}\text { Axillary, } \\
50 \mathrm{ml}\end{array}$ & 10 & $11(P=N S)$ & $18 \%$ EP & Splanchnic perfusion OK \\
\hline \multirow[t]{2}{*}{$\begin{array}{l}\text { Michelet and } \\
\text { colleagues }[40]^{\dagger}\end{array}$} & 20 & No & NR & $\begin{array}{l}\text { Symph., } \\
100 \mathrm{ml}\end{array}$ & $\begin{array}{l}\text { Approx. } 6 \\
\text { (foam) }\end{array}$ & $\begin{array}{l}\text { Approx. } 12.5 \\
\quad(P<0.01)\end{array}$ & $10 \%$ EP & No BMI or IAP data reported \\
\hline & & & & & $\begin{array}{l}\text { Approx. } 8 \\
\text { (air) }\end{array}$ & $\begin{array}{l}\text { Approx. } 11 \\
(P<0.05)\end{array}$ & & \\
\hline $\begin{array}{l}\text { Chiumello and } \\
\text { colleagues [44] }\end{array}$ & 11 & Random & 23.1 & $\begin{array}{l}\text { Symph., } \\
100 \mathrm{ml}\end{array}$ & $\begin{array}{c}12 \\
14.5 \text { (not) }\end{array}$ & 14.5 (suspended) & $27 \%$ EP & Suspension not required \\
\hline Fletcher [42] & 10 & No & NR & $\begin{array}{l}\text { Axillary, } \\
50 \mathrm{ml}\end{array}$ & 14.5 & $\begin{array}{l}8.4 \text { to } 11.4^{9} \\
(P=0.0002)\end{array}$ & $100 \%$ DP & Proning does not increase IAP \\
\hline
\end{tabular}

ARDS, acute respiratory distress syndrome; axillary, mid-axillary line; BMI, body mass index; DP, direct pulmonary; EP, extrapulmonary; FRC, forced residual capacity; IAP, intra-abdominal pressure; NA, not applicable; NR, not reported; symph., pubic symphysis. aZero, reference point for IAP measurement; prime, priming volume for IAP measurement if intermittent bladder pressure measurement used. ${ }^{\mathrm{b}}$ Acute respiratory distress syndrome with best classification from reported data. ${ }^{\mathrm{C}}$ No IAP measurements. ${ }^{d}$ Sixteen patients were in the main study but only 10 had IAP measured. eNo numerical IAP data reported only graphical results presented in this comparison of air-cushioned mattresses versus foam mattresses. ${ }^{f}$ Gastric pressure measurements. ${ }^{9}$ Time series regression analysis of hourly IAP measurements.

was significantly different after proning on the conventional mattress; however, changes in the disappearance rate of indocyanine green were not correlated with IAP changes [40]. Similarly, Kiefer and colleagues found that $\mathrm{MV}$ in PP may be associated with increased gastricmucosal gradients of the partial pressure of carbon dioxide. Although there were major inter-individual variations, the mucosal $\mathrm{pH}$ gradient also increased in nine out of 11 patients in whom IAP increased [43]. Hering and colleagues found that while the renal fraction of cardiac output decreased and renal vascular resistance increased, there were no other important physiological changes and no differences in hepatic function or gastric mucosal carbon dioxide tension compared with the supine position [39].

As an aggregate, none of these studies involved a population with severe IAH, and only two studies (25\%) reported BMI data. Not considering the effect of IAP as a potential consequence of PV needs to be interpreted in light of the fact that IAP changes of as little as $3 \mathrm{mmHg}$ 
Table 3. Consideration of relevant intra-abdominal conditions in randomized trials and meta-analyses concerning prone position ventilation

\begin{tabular}{|c|c|c|c|c|}
\hline Study & $\begin{array}{c}\text { Pulmonary vs. } \\
\text { extrapulmonary ARDS/ALI }\end{array}$ & IAP & BMI & Free abdominal suspension? \\
\hline \multicolumn{5}{|c|}{ Randomized controlled studies of ALI/ARDS/acute respiratory failure } \\
\hline Gattinoni and colleagues [4] & $76 \%$ DP & NR & NR & NR \\
\hline Guerin and colleagues [9] & Partially reported & NR & NR & NR \\
\hline Curley and colleagues [48] ${ }^{\mathrm{a}}$ & $84 \%$ DP & NR & NR & Suspended \\
\hline Papazian and colleagues [13] & $79 \%$ DP & NR & NR & No suspension \\
\hline Voggenreiter and colleagues [49] & NR & NR & NR & NR \\
\hline Mancebo and colleagues [10] & $62 \% \mathrm{DP}$ & NR & NR & NR \\
\hline Chan and colleagues [14] & $100 \%$ DP & NR & NR & No suspension \\
\hline Demory and colleagues [51 $]^{\mathrm{b}}$ & $91 \%$ DP & NR & NR & No suspension \\
\hline Fernandez and colleagues [11] & $65 \%$ DP & NR & $N R^{c}$ & $N R$ \\
\hline Taccone and colleagues [12] & $>65 \% \mathrm{DP}^{d}$ & NR & $25.3^{e}$ & No suspension ${ }^{f}$ \\
\hline \multicolumn{5}{|c|}{ Other randomized controlled studies of prone ventilation } \\
\hline Beuret and colleagues [50]9 & NA & NC & NC & No suspension \\
\hline \multicolumn{5}{|l|}{ Meta-analyses } \\
\hline Alsaghir and Martin [7] & NC & NC & NC & NC \\
\hline Tiruvoipati and colleagues [8] & Partially ${ }^{h}$ & NC & NC & NC \\
\hline Sud and colleagues [18] & NC & NC & NC & NC \\
\hline Abroug and colleagues [19] & NR & NC & NC & NC \\
\hline Kopterides and colleagues [17] & NC & NC & NC & NC \\
\hline Sud and colleagues [52] & NC & NC & NC & NC \\
\hline
\end{tabular}

ALI, acute lung injury; ARDS, acute respiratory distress syndrome; BMI, body mass index; DP, direct pulmonary; IAP, intra-abdominal pressure; NA, not applicable; NC,

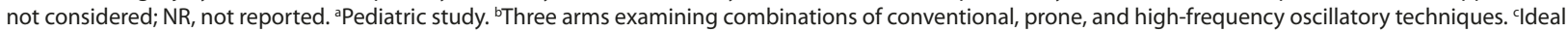
body weight only reported. 'Sixty-five percent direct pulmonary, $6.5 \%$ sepsis and trauma, $23 \%$ other. ${ }^{e}$ Mean population BMI, but not controlled for. ${ }^{f}$ Eighty percent not possible to suspend, $20 \%$ not reported. ${ }^{9}$ Evaluated prone ventilation in setting of coma. ${ }^{h}$ Examines reporting of the most frequent cause of respiratory failure.

after proning were associated with increased gastric mucosal-arterial gradients of partial pressure of carbon dioxide [43]. Further, the effects of even modest IAH in critical illness may be subtle in the setting of multiple organ failure [46], and pressures as low as $10 \mathrm{mmHg}$ may have significant end organ effects [47].

\section{Abdominal considerations in randomized studies of prone ventilation for ALI/ARDS}

The first large randomized controlled trial (RCT) of prone ventilation for ALI/ARDS was reported by Gattinoni and colleagues in 2001 [4]. This trial was followed by nine others in rapid succession, with the largest completed in 2009 [9-14,45,48,49], in addition to studies examining PV with concurrent additional therapies or related respiratory techniques $[9,50,51]$ (Table 3 ). Six meta-analyses were subsequently published $[7,8,17-19,52]$. Nine out of 10 RCTs studying ALI/ARDS distinguished or provided descriptions to allow classification into pulmonary and extrapulmonary groups, although only one meta-analysis considered this factor (Table 3). No study considered IAP or BMI in the design. In terms of the proning technique, one RCT reported free suspension, four trials reported specifically not, and five trials did not discuss suspension. No meta-analysis considered abdominal suspension.

\section{Discussion}

Small studies in selected patients without IAH have demonstrated modest elevations in IAP without marked physiologic effects after proning. Despite the increasing recognition of the importance of thoracoabdominal interactions, no animal or clinical study has specifically addressed these interactions in a population with either IAH or obesity. The evidence as to whether proning itself induces important changes in IAP therefore remains inconsistent and is unhelpful to guide clinical practice.

The use of PV in ALI/ARDS appears to be decreasing, presumably due to the inability of RCTs to demonstrate a survival advantage using a technique that requires great logistical input and has significant side effects [19,52,53]. Although a number of methodological reasons have been previously discussed [19], we suggest an additional factor to be considered when interpreting previous clinical and physiological studies on PV: the role of the 
thoracoabdominal cavity as a complete entity, and the lack of appreciation for the relationship between IAP and intra-abdominal volume (IAV) reflecting abdominal compliance $(\mathrm{Cab})$.

\section{Physiology of prone ventilation}

Achieving improved gas exchange through proning has been variably attributed to improvements in gradients of transpulmonary pressures from chest wall mechanics, in homogeneity of lung inflation, in recruitment of the dorsal lung relative to ventral derecruitment, in increases of end-expiratory lung volumes, in redirection of the compressive forces of the heart weight, in better secretion clearance, or in interactions of all the above $[16,18,33$, $36,37,44,50,54]$. No matter what the exact mechanism is, however, the presence of atelectasis and lung recruitability is the simplest reason for the PV value [55].

\section{Pulmonary versus extrapulmonary ALI/ARDS and the abdomen}

Extrapulmonary and pulmonary subtypes of ALI/ARDS have been reported to differ greatly in their respiratory mechanics, in their response to positive end-expiratory pressure (PEEP), in lung recruitment, and in prone positioning [21,24-26]. Gattinoni and colleagues demonstrated significant IAP differences with either pulmonary or extrapulmonary ALI/ARDS - with mean values of $8.5 \mathrm{mmHg}$ versus $22 \mathrm{mmHg}$, respectively - and changes in chest wall elastance [24]. Extrapulmonary ALI/ARDS from conditions frequently associated with IAH, such as intra-abdominal sepsis or trauma, were thus considered cases that would most benefit from PV. Protti and colleagues discussed prone responders using a wet sponge model in which the greater the lung weight, the greater the collapse and the greater the recruitment potential [3]. Heavier lungs were associated with decreases in carbon dioxide that were associated with increased recruitability [3]. Since the juxtadiaphragmaticdependent regions frequently compressed in ALI/ARDS appeared less amenable to recruitment using higher PEEP, which may simply overdistend aerated nondependent lung regions [56,57], PV offers a potential recruitment technique that focuses on the most gravitationally at-risk lung regions.

Animal models have clearly illustrated differing pathology between extrapulmonary and intrapulmonary ALI/ARDS $[27,58,59]$, as well as generally greater responsiveness to recruitment maneuvers in extrapulmonary ALI/ARDS $[26,28]$. The critically ill human is much more complex, however, and investigators have not consistently confirmed greater lung recruitability within these subgroups of the ALI/ARDS population, or even to consistently subtype accurately $[60,61]$. Missing data continue to be the chest wall mechanics, abdominal status, and IAP [60]. We question whether the difficulty in accurately categorizing ALI/ARDS into two subgroups in order to predict prone responsiveness is necessary, and whether simply considering the abdominal status with easily measured parameters such as IAP might guide the clinician better. This is congruous with the opinion of Talmor and colleagues, who recently noted markedly improved respiratory parameters in ALI/ARDS patients with PEEP selected based on esophageal pressures [62]. They suggested that disappointing results utilizing algorithmic PEEP adjustments may relate to the lack of recognition of elevated pleural or IAP [62]. We therefore question whether the etiology of ALI/ARDS is critical or whether, instead, the relative changes in lung and chest wall mechanics including IAP should be the focus for future subtyping of ALI/ARDS. In reference to PV, however, this hypothesis has not been tested to date, as no prospective RCTs evaluating PV have considered measuring, reporting, or stratifying by either IAP or BMI.

\section{Abdominal morphology}

Abdominal morphology intuitively plays a central role in a technique involving positioning the critically ill patient upon their abdomen. Treating the abdomen as a limited elastic body [63] illustrates how initial modest volume increases may be accommodated with modest pressure increases, but further increases beyond a pressurevolume curve inflection point will be associated with IAH $[45,64]$ (Figure 1). Initial work supports the contention that the amplitude of IAP oscillation with ventilation may infer the abdominal compliance $[64,65]$. Essentially, a stiffer abdomen may be indicated by greater fluctuations and higher peaks from physical compression than more compliant abdomens. Cab may thus at least partially explain the variability in abdominothoracic pressure transmission ratios $[66,67]$. Identifying the degree of stiffness or lack thereof may therefore help identify patients at risk for adverse effects of IAH in general, and from prone abdominal compression in particular.

\section{Technique: thoracopelvic supports to suspend the abdomen}

Thoracopelvic supports are any support specifically used to direct the prone patient's body weight upon the chest and pelvic bones, to suspend and thereby unencumber the abdomen. Healthy volunteers who simulated patients had significantly increased contact pressures at the chest and pelvic locations during PP [44] This positioning decreases chest wall movements and reduces thoracoabdominal compliance (increasing stiffness or elastance). We believe that thoracopelvic support are required for at least three reasons in many if not all patients undergoing PV for respiratory reasons: to redistribute ventilatory gasses towards the now dependent ventral and 


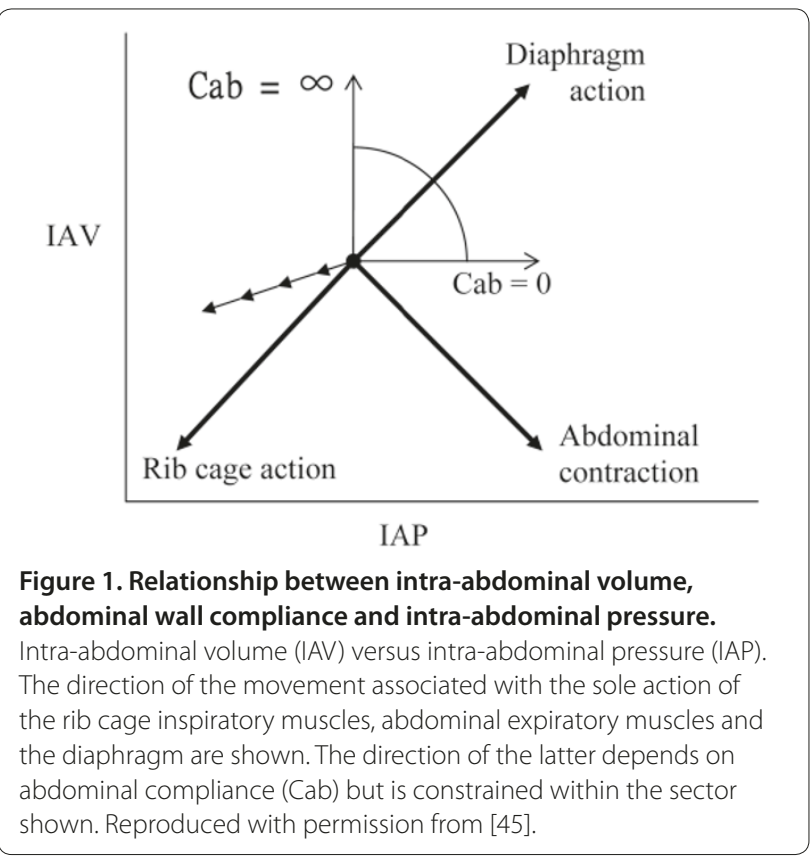

diaphragmatic regions where minimal atelectasis and collapse are present [34,36]; to avoid compressing a noncompliant distended abdomen, especially if IAH is present; and to potentially unload an abdomen off the lungs with sufficient $\mathrm{Cab}$ to allow this, as will be explained.

\section{Gravitational abdominal unloading}

Supine positioning compresses the dependent lung bases with collapse and reduces lung volumes in normal patients (Figure 2a), and is worse with obesity or severe IAH $[68,69]$ (Figure 2b). The end-expiratory lung volume may be less than one-half after the induction of anesthesia in obese patients [69], and the degree of atelectasis correlates with body weight [68]. When gravity is removed from supine pigs in parabolic flight, tidal volumes with constant ventilation significantly increase with both normal IAP and $\mathrm{IAH}$, presumably as the abdominal weight is effectively removed [70] (Figure 2c). While treating critically ill patients in weightlessness is impractical, prone ventilation largely accomplishes the same effect.

In certain studies, PV increased the end-expiratory lung volume and the forced residual capacity coincident with increased chest wall elastance when the abdomen was suspended $[37,71]$. While there has been no study in severe IAH or overt ACS, data describing obese patients who may be considered a surrogate - do exist. Pelosi and

(a)
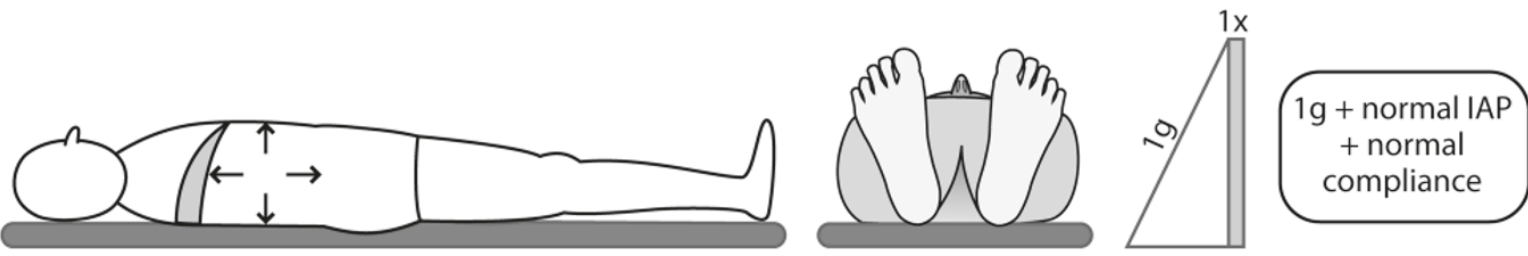

(b)
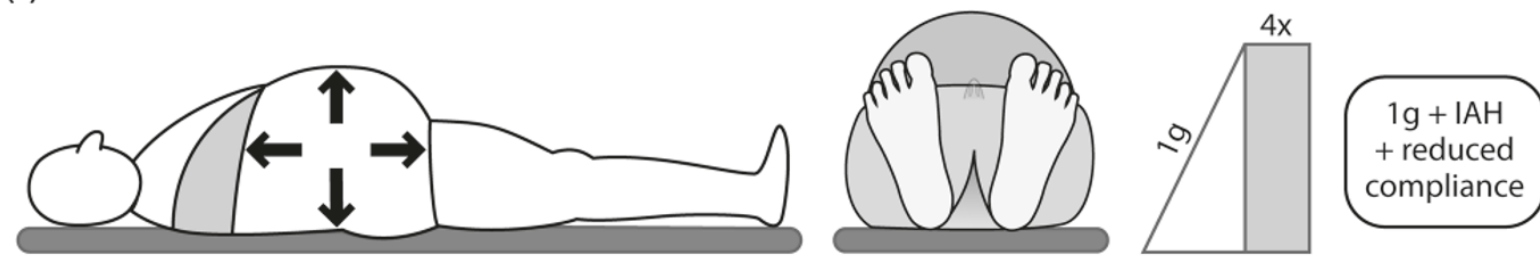

(c)
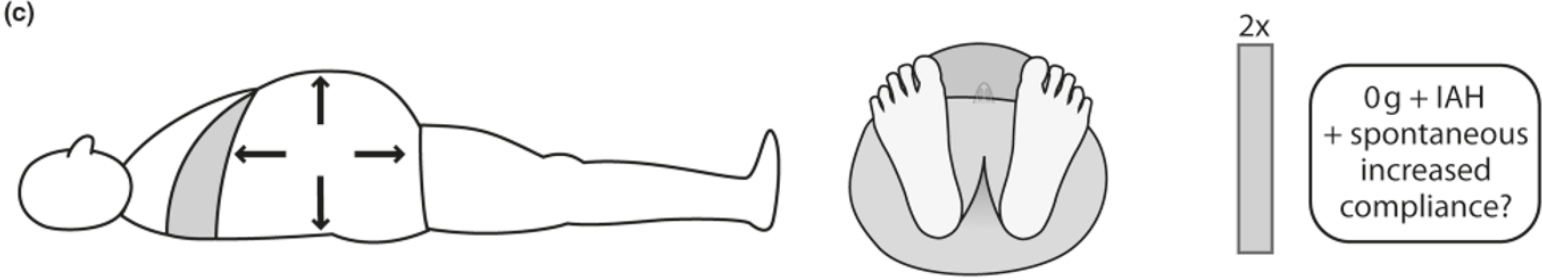

Figure 2. Proposed conceptual thoracoabdominal relationships related to prone ventilation. Proposed conceptual thoracoabdominal relationships related to prone ventilation in varying settings of intra-abdominal pressure (IAP), abdominal volume, abdominal compliance, patient position and gravity. (a) Normal IAP, normal body mass index, normal gravity supine, normal abdominal compliance. (b) Intra-abdominal hypertension (IAH) or obesity in the supine position. (c) IAH in weightlessness results in greater lung volumes and spontaneous conformational changes to the abdominal wall. 
(a)
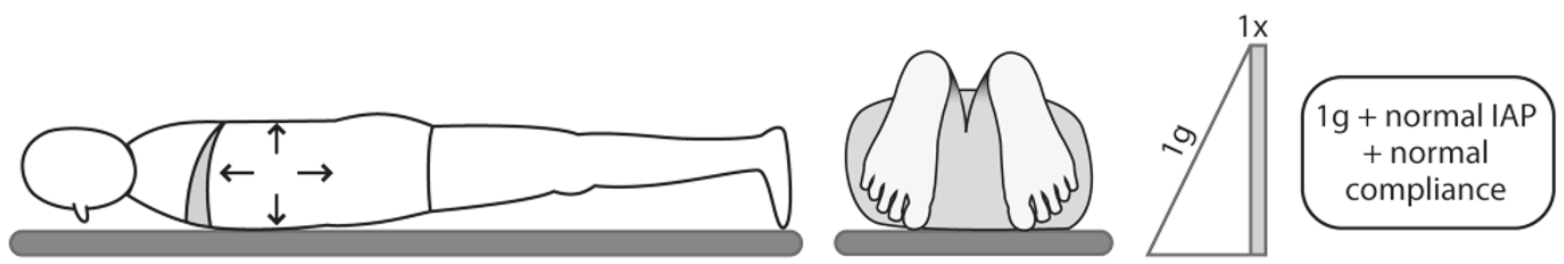

(b)
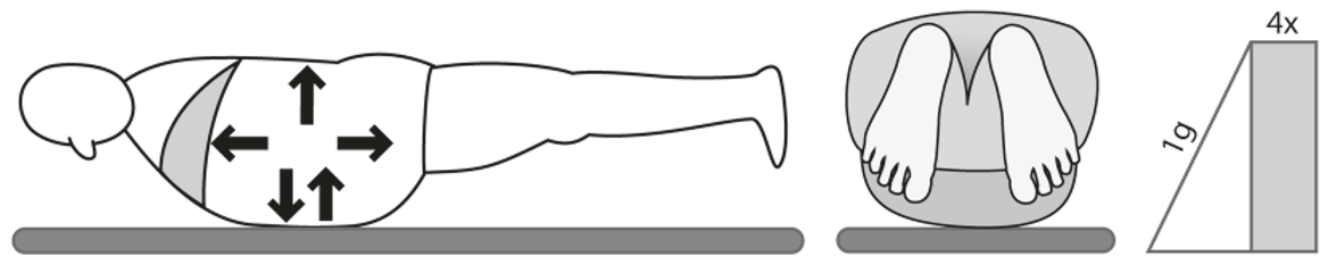

$1 \mathrm{~g}+\mathrm{IAH}$

+ reduced

compliance

(c)
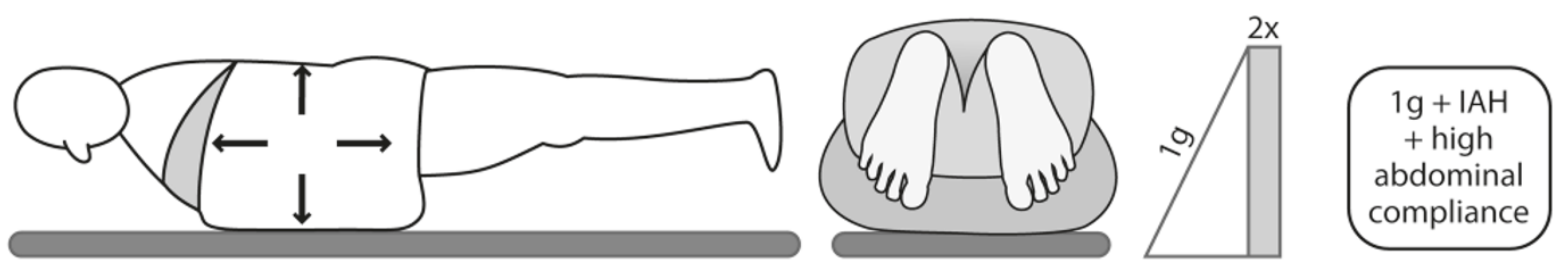

(d)
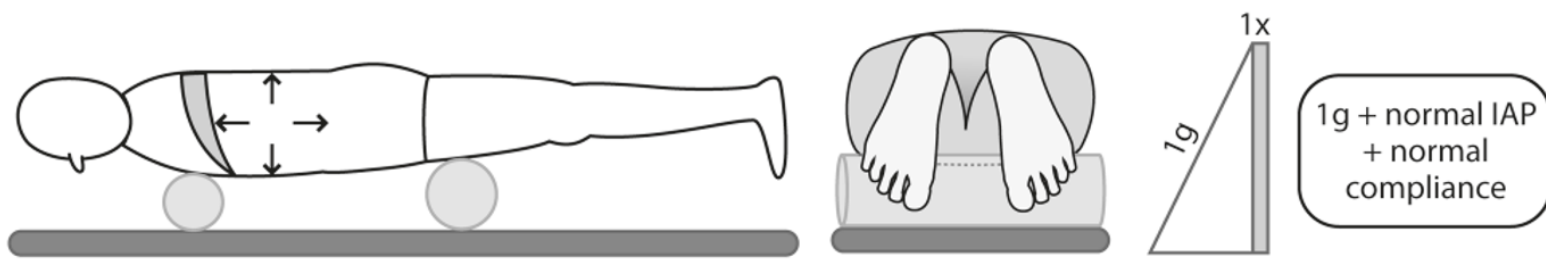

(e)
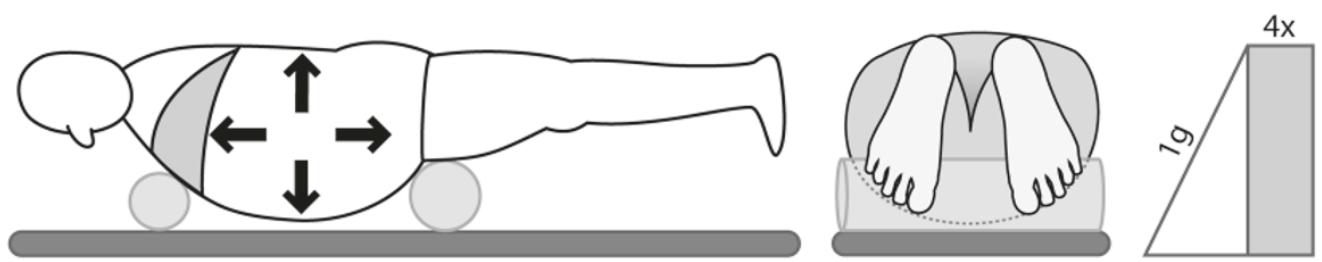

$1 \mathrm{~g}+\mathrm{IAH}$

+ low abdominal compliance

(f)
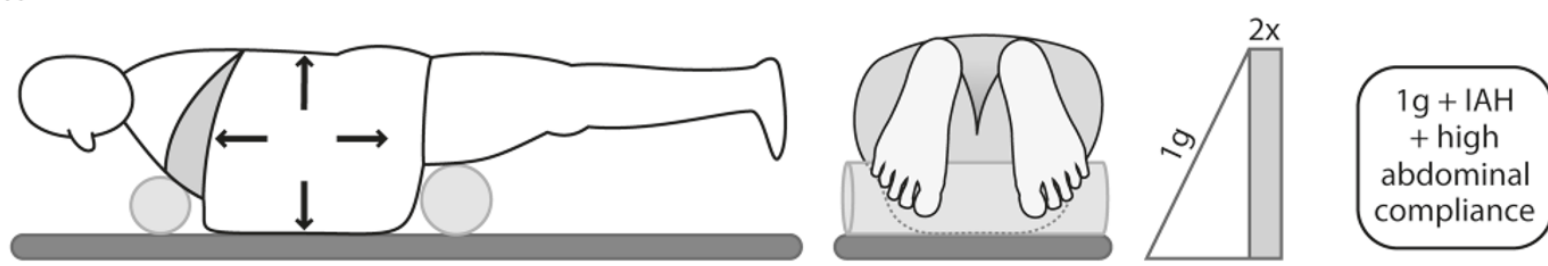

Figure 3. Integrated theory of abdominal pressure and morphology in relation to prone positioning and prone ventilation. (a) Normal intraabdominal pressure (IAP) with no abdominal volume and compliance proned. (b) Intra-abdominal hypertension (IAH) with increased abdominal volume and decreased abdominal compliance. (c) IAH with increased abdominal volume but normal or increased abdominal compliance results in a splashed out abdomen. (d) Prone positioning on thoracopelvic supports with normal IAP and normal abdominal volume. (e) Prone positioning on thoracopelvic supports with IAH and decreased abdominal compliance so that lung bases are not decompressed. (f) Prone positioning on thoracopelvic supports with IAH but normal or increased abdominal compliance so that lung bases are gravitationally decompressed. 
Extravascular lung water index

Fluid balance

Body anthropomorphic data

Presence or absence of ascites

Intrathoracic pressure (ideally esophageal pressure and transdiaphragmatic pressure gradient)

Chest wall compliance (as a benefit of measuring intrathoracic pressure)

Etiology of acute lung injury/acute respiratory distress syndrome

Duration of prone ventilation

Technique of prone ventilation

Use or nonuse of thoracopelvic supports and exact position of supports

Total respiratory compliance

Lung compliance

Lower inflection point

Upper inflection point

colleagues investigated patients undergoing surgical procedures in PP and ensuring free abdominal movements and gravitational unloading [36,37,71]. With such attention there were marked increases in the oxygenation and forced residual capacity of patients in PP versus supine positioning (1.9 l versus 2.91 ) with a normal BMI of 23.2 [71], and an increase of 0.89 to 1.981 in those with an obese BMI of 34.6 [37]. Especially in obese patients, decreased chest wall compliance in PP was offset by increased lung compliance [37]. They hypothesized that increases in forced residual capacity were due to reductions in cephalad diaphragmatic pressures from abdominal visceral unloading or reopening of atelectatic segments $[37,71]$. While it might be predicted that such lower lung unloading would be associated with a decreased IAP, these measurements were not made and the prediction remains speculation.

Although IAP was not a focus, these studies provide the best guidance regarding proning with IAH, as obesity is well linked to chronic IAH, which compresses the lungs and decreases forced residual capacity [72]. We therefore speculate that, in general, the greater the abdominal distension (larger IAV), the higher the BMI and that the higher the IAP, the more important it is to ensure that the visceral abdominal mass is subjected to downwards gravitational forces rather than allowing IAV to be compressed up into the thorax, inducing atelectasis and reducing lung volumes.

An integrated theory of abdominal pressure and morphology in relation to prone positioning

We hypothesize that whether IAP increases or decreases in relation to PV may be a function of how tight the abdomen is and whether it is compressed or decompressed by the act of proning. If an abdomen is obese or distended, placing the full body weight face down would intuitively lead to compression of the contents against the rigid dorsal abdominal wall. This compresses the lung bases and induces atelectasis, as seen under general anesthesia - especially after muscle relaxant administration [37]. In the critically ill patient with normal IAP, the abdomen is not compressed when proned even if unsuspended and typically only beneficial physiologic effects of proning are seen (Figure 3a). When the patient has a large abdomen (that is, large IAV) that protrudes beyond the ribcage when standing upright or when supine), then clinicians should consider the risk that the IAP will rise if the abdomen is unsuspended - thus compressing the lung bases (Figure $3 \mathrm{~b}$ ). With a smaller IAV, this compressing effect will be minimal or absent (Figure 3a). In some cases, however, IAP may be acceptable when compliance is high - as might occur with chronic increases in IAV such as pregnancy or gradually accumulated ascites, wherein the abdomen will be splashed out if unsupported (Figure 3c). While formal elasticity was not calculated, Abu-Rafea and colleagues showed that the parity of women undergoing laparoscopy positively correlated with a need for greater volumes of insufflated gas to reach target pressures [73]. Conversely, if the same IAV was contained within a noncompliant abdomen, reflecting many cases of acute IAH, and the contents were compressed by body weight, then IAP would predictably increase greatly.

Acute rises in IAP typical with IAH/ACS will typically be associated with decreased abdominal compliance. To avoid further embarrassing injured lungs in these 
patients, therefore, we believe abdominal suspension is required for those patients with acute IAH - to possibly unload the abdomen off the juxtadiaphragmatic lung regions, but to certainly avoid compressing the abdomen and worsening IAH. Whether the former improvements occur with suspension, however, probably depends on the Cab. Akin to Figure 3a, if IAP is normal then proning with or without suspension will not markedly affect the IAP [44] (Figure 3d). Further, in a theoretical patient with very low compliance and moderate IAH, proning will not unload the lung bases even when the abdomen is suspended (Figure 3e). Alternatively, when compliance is high and the abdomen is suspended, the abdominal contents would be decompressed away from the juxtadiaphragmatic lung and additional benefits will be observed (Figure 3f). Whether simple interventions such as percutaneous drainage of intraperitoneal fluid [74] could increase the Cab in cases of acute IAH, and could increase the effects of proning, remains speculative but deserves further study. Investigators attempting to truly understand the merits of PV should thus consider IAP and related parameters (Table 4).

\section{Conclusions}

The chest and abdomen are inexorably linked and must be considered as a single unit. Many critical illnesses culminate in abdominal distension that - along with obesity - often induces IAH, with adverse effects throughout the body but particularly in the lungs. Despite the effort devoted to studies of PV, the potentially confounding issues of IAH have been largely neglected. Even the act of PP appears to have the potential to either exacerbate or ameliorate IAH, depending on the technique, yet these details are often lacking in reports. The authors speculate that utilizing a proning technique that unloads the abdomen in ALI/ARDS populations with prominent lung atelectasis complicated/induced by IAH/obesity may be optimal to test the true merits of PV. This hypothesis, however, will need to await confirmation or refutation in a prospective study. Currently, however, clinicians should remain cognizant of the fact that depending on the mechanics used - proning activities have the potential to induce IAH, which can definitely adversely influence the respiratory outcomes.

\section{Abbreviations}

ACS, abdominal compartment syndrome; ALI, acute lung injury; ARDS, acute respiratory distress syndrome; BMI, body mass index; Cab, abdominal wall compliance; IAH, intra-abdominal hypertension; IAP, intra-abdominal pressure; $I A V$, intra-abdominal volume; MV, mechanical ventilation; PEEP, positive end-expiratory pressure; $\mathrm{PP}$, prone positioning; PV, prone ventilation; $\mathrm{RCT}$, randomized controlled trial.

\section{Competing interests}

MLNGM has consulted for and has stock ownership with Pulsion Medical Systems, has received patent support from Pulsion Medical Systems, and has also received royalties from Holtech Medical. The remaining authors state that they have no competing interests.

\section{Acknowledgements}

The authors thank Sandy Cochrane, Multimedia Services, University of Calgary, for her artistry, creativity, and practicality in illustration.

\section{Author details}

'Regional Trauma Services, Foothills Medical Centre, 140329 Street NW, Calgary, Alberta, Canada T2N 2T9. ${ }^{2}$ Department of Surgery, Calgary Heath Region and Foothills Medical Centre, 140329 Street NW, Calgary, Alberta, Canada T2N 2T9. ${ }^{3}$ Department of Critical Care Medicine, Calgary Heath Region and Foothills Medical Centre, 140329 Street NW, Calgary, Alberta, Canada T2N 2T9. ${ }^{4}$ Department of Environment, Health and Safety, University of Insubria, c/o Villa Toeplitz Via G.B. Vico, 4621100 Varese, Italy. ${ }^{5}$ Department of Critical Care Medicine, Ghent University Hospital, De Pintelaan 185, 9000 Gent, Belgium. IIntensive Care Unit, Ziekenhuis Netwerk Antwerpen, ZNA Stuivenberg, Lange Beeldekensstraat 267, B-2060 Antwerpen 6, Belgium. 'Department of Medicine, Room 2C10, McMaster University Medical Centre, 1200 Main Street West, Hamilton, Ontario, Canada L8N 3Z5. ${ }^{8}$ Department of Clinical Epidemiology and Biostatistics, Room 2C10, McMaster University Medical Centre, 1200 Main Street West, Hamilton, Ontario, Canada L8N $3 Z 5$.

Published: 27 August 2010

\section{References}

1. Gattinoni L, Protti A: Ventilation in the prone position: for some but not for all? CMAJ 2008, 178:1174-1176.

2. Slutsky AS: Lung injury caused by mechanical ventilation. Chest 1999, 116(1 Suppl):9S-15S.

3. Protti A, Chiumello D, Cressoni M, Carlesso E, Mietto C, Berto V, Lazzerini M, Quintel M, Gattinoni L: Relationship between gas exchange response to prone position and lung recruitability during acute respiratory failure. Intensive Care Med 2009, 35:1011-1017.

4. Gattinoni L, Tognoni G, Pesenti A, Taccone P, Mascheroni D, Labarta V, Malacrida R, Di Giulio P, Fumagalli R, Pelosi P, Brazzi L, Latini R: Effect of prone positioning on the survival of patients with acute respiratory failure. NEngl J Med 2001, 345:568-573.

5. Slutsky AS: Improving outcomes in critically ill patients: the seduction of physiology. JAMA 2009, 302:2030-2032.

6. Slutsky AS: The acute respiratory distress syndrome, mechanical ventilation, and the prone position. N Engl J Med 2001, 345:610-612.

7. Alsaghir AH, Martin CM: Effect of prone positioning in patients with acute respiratory distress syndrome: a meta-analysis. Crit Care Med 2008, 36:603-609.

8. Tiruvoipati R, Bangash M, Manktelow B, Peek GJ: Efficacy of prone ventilation in adult patients with acute respiratory failure: a meta-analysis. J Crit Care 2008, 23:101-110.

9. Guerin C, Gaillard S, Lemasson S, Ayzac L, Girard R, Beuret P, Palmier B, Le QV, Sirodot M, Rosselli S, Cadiergue V, Sainty JM, Barbe P, Combourieu E, Debatty D, Rouffineau J, Ezingeard E, Millet O, Guelon D, Rodriguez L, Martin O, Renault A, Sibille JP, Kaidomar M: Effects of systematic prone positioning in hypoxemic acute respiratory failure: a randomized controlled trial. JAMA 2004, 292:2379-2387.

10. Mancebo J, Fernandez R, Blanch L, Rialp G, Gordo F, Ferrer M, Rodriguez F, Garro P, Ricart P, Vallverdu I, Gich I, Castano J, Saura P, Dominguez G, Bonet A, Albert RK: A multicenter trial of prolonged prone ventilation in severe acute respiratory distress syndrome. Am J Respir Crit Care Med 2006, 173:1233-1239.

11. Fernandez R, Trenchs X, Klamburg J, Castedo J, Serrano JM, Besso G, Tirapu JP, Santos A, Mas A, Parraga M, Jubert P, Frutos F, Anon JM, Garcia M, Rodriguez F, Yebenes JC, Lopez MJ: Prone positioning in acute respiratory distress syndrome: a multicenter randomized clinical trial. Intensive Care Med 2008, 34:1487-1491.

12. Taccone P, Pesenti A, Latini R, Polli F, Vagginelli F, Mietto C, Caspani L, Raimondi F, Bordone G, lapichino G, Mancebo J, Guerin C, Ayzac L, Blanch L, Fumagalli R, Tognoni G, Gattinoni L: Prone positioning in patients with moderate and severe acute respiratory distress syndrome: a randomized controlled trial. JAMA 2009, 302:1977-1984.

13. Papazian L, Gainnier M, Marin V, Donati S, Arnal JM, Demory D, Roch A, Forel $J M$, Bongrand P, Bregeon F, Sainty JM: Comparison of prone positioning and high-frequency oscillatory ventilation in patients with acute respiratory distress syndrome. Crit Care Med 2005, 33:2162-2171.

14. Chan MC, Hsu JY, Liu HH, Lee YL, Pong SC, Chang LY, Kuo BI, Wu CL: Effects of 
prone position on inflammatory markers in patients with ARDS due to community-acquired pneumonia. J Formos Med Assoc 2007, 106:708-716.

15. Santana MC, Garcia CS, Xisto DG, Nagato LK, Lassance RM, Prota LF, Ornellas FM, Capelozzi VL, Morales MM, Zin WA, Pelosi P, Rocco PR: Prone position prevents regional alveolar hyperinflation and mechanical stress and strain in mild experimental acute lung injury. Respir Physiol Neurobio/ 2009, 167:181-188.

16. Valenza F, Guglielmi M, Maffioletti M, Tedesco C, Maccagni P, Fossali T, Aletti G, Porro GA, Irace M, Carlesso E, Carboni N, Lazzerini M, Gattinoni L: Prone position delays the progression of ventilator-induced lung injury in rats: does lung strain distribution play a role? Crit Care Med 2005, 33:361-367.

17. Kopterides P, Siempos, II, Armaganidis A: Prone positioning in hypoxemic respiratory failure: meta-analysis of randomized controlled trials. J Crit Care 2009, 24:89-100.

18. Sud S, Sud M, Friedrich JO, Adhikari NK: Effect of mechanical ventilation in the prone position on clinical outcomes in patients with acute hypoxemic respiratory failure: a systematic review and meta-analysis. CMAJ 2008, 178:1153-1161.

19. Abroug F, Ouanes-Besbes $L$, Elatrous $S$, Brochard $L$ : The effect of prone positioning in acute respiratory distress syndrome or acute lung injury: a meta-analysis. Areas of uncertainty and recommendations for research. Intensive Care Med 2008, 34:1002-1011.

20. Bernard GR, Artigas A, Brigham KL, Carlet J, Falke K, Hudson L, Lamy M, Legall JR, Morris A, Spragg R: The American-European Consensus Conference on ARDS. Definitions, mechanisms, relevant outcomes, and clinical trial coordination. Am J Respir Crit Care Med 1994, 149:818-824.

21. Pelosi P, Gattinoni L: Acute respiratory distress syndrome of pulmonary and extra-pulmonary origin: fancy or reality? Intensive Care Med 2001, 27:457-460.

22. Ranieri VM, Brienza N, Santostasi S, Puntillo F, Mascia L, Vitale N, Giuliani R, Memeo V, Bruno F, Fiore T, Brienza A, Slutsky AS: Impairment of lung and chest wall mechanics in patients with acute respiratory distress syndrome: role of abdominal distension. Am J Respir Crit Care Med 1997, 156:1082-1091.

23. Pelosi P, Caironi P, Gattinoni L: Pulmonary and extrapulmonary forms of acute respiratory distress syndrome. Semin Respir Crit Care Med 2001 22:259-268.

24. Gattinoni L, Pelosi P, Suter PM, Pedoto A, Vercesi P, Lissoni A: Acute respiratory distress syndrome caused by pulmonary and extrapulmonary disease. Different syndromes? Am J Respir Crit Care Med 1998, 158:3-11.

25. Lim CM, Kim EK, Lee JS, Shim TS, Lee SD, Koh Y, Kim WS, Kim DS, Kim WD: Comparison of the response to the prone position between pulmonary and extrapulmonary acute respiratory distress syndrome. Intensive Care Med 2001, 27:477-485

26. Rocco PR, Pelosi P: Pulmonary and extrapulmonary acute respiratory distress syndrome: myth or reality? Curr Opin Crit Care 2008, 14:50-55.

27. Leite-Junior JH, Garcia CS, Souza-Fernandes AB, Silva PL, Ornellas DS, Larangeira AP, Castro-Faria-Neto HC, Morales MM, Negri EM, Capelozzi VL, Zin WA, Pelosi P, Bozza PT, Rocco PR: Methylprednisolone improves lung mechanics and reduces the inflammatory response in pulmonary but not in extrapulmonary mild acute lung injury in mice. Crit Care Med 2008, 36:2621-2628

28. Riva DR, Oliveira MB, Rzezinski AF, Rangel G, Capelozzi VL, Zin WA, Morales MM, Pelosi P, Rocco PR: Recruitment maneuver in pulmonary and extrapulmonary experimental acute lung injury. Crit Care Med 2008, 36:1900-1908.

29. Malbrain ML, Cheatham ML, Kirkpatrick A, Sugrue M, Parr M, De Waele J, Balogh Z, Leppaniemi A, Olvera C, Ivatury R, D'Amours S, Wendon J, Hillman K, Johansson K, Kolkman K, Wilmer A: Results from the International Conference of Experts on Intra-abdominal Hypertension and Abdominal Compartment Syndrome. I. Definitions. Intensive Care Med 2006, 32:1722-1732.

30. Malbrain ML, Chiumello D, Pelosi P, Bihari D, Innes R, Ranieri VM, Del Turco M, Wilmer A, Brienza N, Malcangi V, Cohen J, Japiassu A, Keulenaer BL, Daelemans R, Jacquet L, Laterre PF, Frank G, de Souza P, Cesana B, Gattinoni L: Incidence and prognosis of intraabdominal hypertension in a mixed population of critically ill patients: a multi-center epidemiological study. Crit Care Med 2005, 33:315-322.

31. Malbrain ML: Is it wise not to think about intraabdominal hypertension in the ICU? Curr Opin Crit Care 2004, 10:132-145.

32. Bryan AC: Comments of a devils advocate. Am Rev Respir Dis 1974, 110:143-144.
33. Douglas WW, Rehder K, Beynen FM, Sessler AD, Marsh HM: Improved oxygenation in patients with acute respiratory failure: the prone position. Am Rev Respir Dis 1977, 115:559-566.

34. Mure M, Glenny RW, Domino KB, Hlastala MP: Pulmonary gas exchange improves in the prone position with abdominal distension. Am J Respir Crit Care Med 1998, 157(6 Pt 1):1785-1790.

35. Colmenero-Ruiz M, Pola-Gallego de Guzman D, Jimenez-Quintana MM, Fernandez-Mondejar E: Abdomen release in prone position does not improve oxygenation in an experimental model of acute lung injury. Intensive Care Med 2001, 27:566-573.

36. Pelosi P, Tubiolo D, Mascheroni D, Vicardi P, Crotti S, Valenza F, Gattinoni L: Effects of the prone position on respiratory mechanics and gas exchange during acute lung injury. Am J Respir Crit Care Med 1998, 157:387-393.

37. Pelosi P, Croci M, Calappi E, Mulazzi D, Cerisara M, Vercesi P, Vicardi P, Gattinoni $L$ : Prone positioning improves pulmonary function in obese patients during general anesthesia. Anesth Analg 1996, 83:578-583.

38. Hering R, Wrigge H, Vorwerk R, Brensing KA, Schroder S, Zinserling J, Hoeft A, Spiegel TV, Putensen C: The effects of prone positioning on intraabdominal pressure and cardiovascular and renal function in patients with acute lung injury. Anesth Analg 2001, 92:1226-1231.

39. Hering R, Vorwerk R, Wrigge H, Zinserling J, Schroder S, von Spiegel T, Hoeft A, Putensen C: Prone positioning, systemic hemodynamics, hepatic indocyanine green kinetics, and gastric intramucosal energy balance in patients with acute lung injury. Intensive Care Med 2002, 28:53-58.

40. Michelet P, Roch A, Gainnier M, Sainty JM, Auffray JP, Papazian L: Influence of support on intra-abdominal pressure, hepatic kinetics of indocyanine green and extravascular lung water during prone positioning in patients with ARDS: a randomized crossover study. Crit Care 2005, 9:R251-R257.

41. Matejovic M, Rokyta R, Jr, Radermacher P, Krouzecky A, Sramek V, Novak I: Effect of prone position on hepato-splanchnic hemodynamics in acute lung injury. Intensive Care Med 2002, 28:1750-1755.

42. Fletcher $\mathrm{SJ}$ : The effect of prone ventilation on intra-abdominal pressure. Clin Intensive Care 2008, 17:109-112.

43. Kiefer P, Morin A, Putzke C, Wiedeck H, Georgieff M, Radermacher P: Influence of prone position on gastric mucosal-arterial $\mathrm{PCO}_{2}$ gradients. Intensive Care Med 2001, 27:1227-1230.

44. Chiumello D, Cressoni M, Racagni M, Landi L, Li Bassi G, Polli F, Carlesso E, Gattinoni L: Effects of thoraco-pelvic supports during prone position in patients with acute lung injury/acute respiratory distress syndrome: a physiological study. Crit Care 2006, 10:R87.

45. De Keulenaer BL, De Waele JJ, Powell B, Malbrain ML: What is normal intraabdominal pressure and how is it affected by positioning, body mass and positive end-expiratory pressure? Intensive Care Med 2009, 35:969-976.

46. Kirkpatrick AW, Balogh Z, Ball CG, Ahmed N, Chun R, McBeth P, Kirby A, Zygun DA: The secondary abdominal compartment syndrome: latrogenic or unavoidable? J Am Coll Surg 2006, 202:668-679.

47. Diebel LN, Dulchavsky SA, Brown WJ: Splanchnic ischemia and bacterial translocation in the abdominal compartment syndrome. J Trauma 1997 43:852-855.

48. Curley MA, Hibberd PL, Fineman LD, Wypij D, Shih MC, Thompson JE, Gran MJ, Barr FE, Cvijanovich NZ, Sorce L, Luckett PM, Matthay MA, Arnold JH: Effect of prone positioning on clinical outcomes in children with acute lung injury: a randomized controlled trial. JAMA 2005, 294:229-237.

49. Voggenreiter G, Aufmkolk M, Stiletto RJ, Baacke MG, Waydhas C, Ose C, Bock E, Gotzen L, Obertacke U, Nast-Kolb D: Prone positioning improves oxygenation in post-traumatic lung injury - a prospective randomized trial. J Trauma 2005, 59:333-341.

50. Beuret P, Carton MJ, Nourdine K, Kaaki M, Tramoni G, Ducreux JC: Prone position as prevention of lung injury in comatose patients: a prospective, randomized, controlled study. Intensive Care Med 2002, 28:564-569.

51. Demory D, Michelet P, Arnal JM, Donati S, Forel JM, Gainnier M, Bregeon F, Papazian L: High-frequency oscillatory ventilation following prone positioning prevents a further impairment in oxygenation. Crit Care Med 2007, 35:106-111.

52. Sud S, Friedrich JO, Taccone P, Polli F, Adhikari NK, Latini R, Pesenti A, Guerin C, Mancebo J, Curley MA, Fernandez R, Chan MC, Beuret P, Voggenreiter G, Sud $M$, Tognoni G, Gattinoni L: Prone ventilation reduces mortality in patients with acute respiratory failure and severe hypoxemia: systematic review and meta-analysis. Intensive Care Med 2010, 36:585-599.

53. Esteban A, Ferguson ND, Meade MO, Frutos-Vivar F, Apezteguia C, Brochard L, Raymondos K, Nin N, Hurtado J, Tomicic V, Gonzalez M, Elizalde J, Nightingale 
P, Abroug F, Pelosi P, Arabi Y, Moreno R, Jibaja M, D'Empaire G, Sandi F, Matamis D, Montanez AM, Anzueto A: Evolution of mechanical ventilation in response to clinical research. Am J Respir Crit Care Med 2008, 177:170-177.

54. Albert RK, Hubmayr RD: The prone position eliminates compression of the lungs by the heart. Am J Respir Crit Care Med 2000, 161:1660-1665.

55. Marini JJ: Prone positioning for ARDS: defining the target. Intensive Care Med 2010, 36:559-561.

56. Puybasset L, Cluzel P, Chao N, Slutsky AS, Coriat P, Rouby Jj: A computed tomography scan assessment of regional lung volume in acute lung injury. The CT Scan ARDS Study Group. Am J Respir Crit Care Med 1998, 158(5 Pt 1):1644-1655.

57. Puybasset L, Gusman P, Muller JC, Cluzel P, Coriat P, Rouby JJ: Regional distribution of gas and tissue in acute respiratory distress syndrome. III. Consequences for the effects of positive end-expiratory pressure. CT Scan ARDS Study Group. Adult Respiratory Distress Syndrome. Intensive Care Med 2000, 26:1215-1227.

58. Menezes SL, Bozza PT, Neto HC, Laranjeira AP, Negri EM, Capelozzi VL, Zin WA, Rocco PR: Pulmonary and extrapulmonary acute lung injury: inflammatory and ultrastructural analyses. J App/ Physiol 2005, 98:1777-1783.

59. Quintel M, Pelosi P, Caironi P, Meinhardt JP, Luecke T, Herrmann P, Taccone P, Rylander C, Valenza F, Carlesso E, Gattinoni L: An increase of abdominal pressure increases pulmonary edema in oleic acid-induced lung injury. Am J Respir Crit Care Med 2004, 169:534-541.

60. Thille AW, Richard JC, Maggiore SM, Ranieri VM, Brochard L: Alveolar recruitment in pulmonary and extrapulmonary acute respiratory distress syndrome: comparison using pressure-volume curve or static compliance. Anesthesiology 2007, 106:212-217.

61. Rouby J: Recruitment in pulmonary and extrapulmonary acute respiratory distress syndrome: the end of a myth? Anesthesiology 2007, 106:203-204.

62. Talmor D, Sarge T, Malhotra A, O'Donnell CR, Ritz R, Lisbon A, Novack V, Loring SH: Mechanical ventilation guided by esophageal pressure in acute lung injury. N Engl J Med 2008, 359:2095-2104

63. Song C, Alijani A, Frank T, Hanna GB, Cuschieri A: Mechanical properties of the human abdominal wall measured in vivo during insufflation for laparoscopic surgery. Surg Endosc 2006, 20:987-990.

64. Sturini E, Saporito A, Sugrue M, Parr MJ, Bishop G, Braschi A: Respiratory variation of intra-abdominal pressure: indirect indicator of abdominal compliance? Intensive Care Med 2008, 34:1632-1637.
65. Malbrain MLNG, De laet I: A new concept: the polycompartment syndrome - Part 1. Int J Intensive Care 2008, 2008:19-24.

66. Malbrain MLNG, De laet I: A new concept: the polycompartment syndrome - Part 2. Int J Intensive Care 2009, 2009:19-25.

67. Wauters J, Wilmer A, Valenza F: Abdomino-thoracic transmission during ACS: facts and figures. Acta Clin Belg Supp/ 2007, 1:200-205.

68. Strandberg A, Tokics L, Brismar B, Lundquist H, Hedenstierna G: Constitutional factors promoting development of atelectasis during anaesthesia. Acta Anaesthesiol Scand 1987, 31:21-24

69. Reinius H, Jonnson L, Gustafsson S, Sundboom M, Duvernoy O, Pelosi P, Hendenstierna G, Freden F: Prevention of atelectasis in morbidly obese patients during general anesthesia and paralysis. Anesthesiology 2009, 111:979-987.

70. Kirkpatrick AW, Keaney M, Hemmelgarn B, Zhang J, Ball CG, Groleau M, Tyssen M, Keyte J, Campbell MR, Kmet L, McBeth P, Broderick TJ: Intra-abdominal pressure effects on porcine thoracic compliance in weightlessness: implications for physiologic tolerance of laparoscopic surgery in space. Crit Care Med 2009, 37:591-597.

71. Pelosi P, Croci M, Calappi E, Cerisara M, Mulazzi D, Vicardi P, Gattinoni L: The prone positioning during general anesthesia minimally affects respiratory mechanics while improving functional residual capacity and increasing oxygen tension. Anesth Analg 1995, 80:955-960

72. Sugerman $\mathrm{H}$, Windsor A, Bessos M, Wolfe L: Intra-abdominal pressure, sagittal abdominal diameter and obesity comorbidity. J Intern Med 1997, 241:71-79.

73. Abu-Rafea B, Vilos GA, Vilos AG, Hollett-Caines J, Al-Omran M: Effect of body habitus and parity on insufflated $\mathrm{CO}_{2}$ volume at various intraabdominal pressures during laparoscopic access in women. J Minim Invasive Gynecol 2006, 13:205-210

74. Reed SF, Britt RC, Collins J, Weireter L, Cole F, Britt LD: Aggressive surveillance and early catheter-directed therapy in the management of intraabdominal hypertension. J Trauma 2006, 61:1359-1365.

doi:10.1186/cc9099

Cite this article as: Kirkpatrick AW, et al: Intra-abdominal hypertension: does it influence the physiology of prone ventilation? Critical Care 2010, 14:232. 